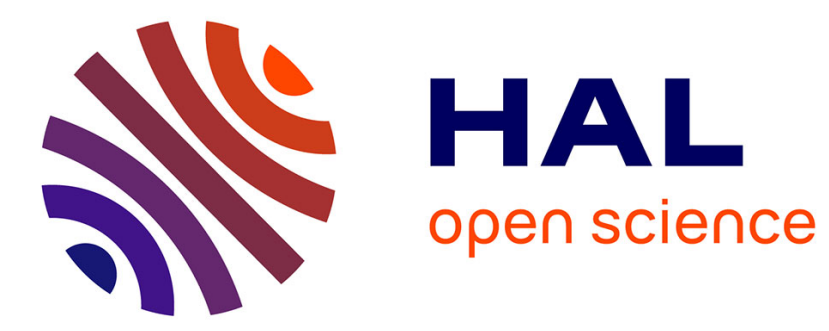

\title{
Microstructure of the coating and mechanical properties of galvanized chromium-rich martensitic steel
}

\author{
E.J. Petit, Y. Grosbety, S. Aden-Ali, J. Gilgert, Z. Azari
}

\section{To cite this version:}

E.J. Petit, Y. Grosbety, S. Aden-Ali, J. Gilgert, Z. Azari. Microstructure of the coating and mechanical properties of galvanized chromium-rich martensitic steel. Surface and Coatings Technology, 2010, 205 (7), pp.2404-2411. 10.1016/j.surfcoat.2010.09.032 . hal-02923710

\section{HAL Id: hal-02923710 \\ https://hal.science/hal-02923710}

Submitted on 27 Aug 2020

HAL is a multi-disciplinary open access archive for the deposit and dissemination of scientific research documents, whether they are published or not. The documents may come from teaching and research institutions in France or abroad, or from public or private research centers.
L'archive ouverte pluridisciplinaire HAL, est destinée au dépôt et à la diffusion de documents scientifiques de niveau recherche, publiés ou non, émanant des établissements d'enseignement et de recherche français ou étrangers, des laboratoires publics ou privés. 


\title{
Microstructure of the coating and mechanical properties of galvanized chromium-rich martensitic steel
}

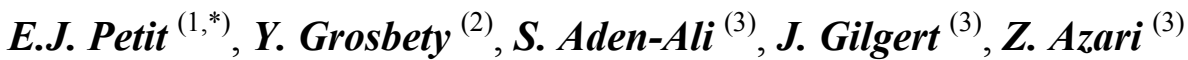
(1) LETAM - FRE3143 (CNRS-UPVM) - Ile du Saulcy - 57000 METZ - France petit@univ-metz.fr ; 00 (33) 3.87.31.53.97 fax : 00 (33) 3.87.31.5.77

(2) Ingénieur CNAM (Conservatoire National des Arts et Métiers) - BEEP - 4, clos des sorbiers, F-57155 Marly - France $\quad$ yves.grosbety@wanadoo.fr; 00 (33) 1.45.92.98.13

(3) ENIM - Ile du Saulcy - 57045 Metz cedex

s.aden-ali@enim.fr; 00 (33) 3.87.34.66.67

gilgert@enim.fr ; 00 (33) 3.87.38.24.79

azari@univ-metz.fr ; 00 (33) 3.87.31.52.69

${ }^{*}$ ) Corresponding author

\begin{abstract}
Protecting the modern high strength steels against corrosion is a challenge because the coating technology must be compatible with forming and must preserve the mechanical performances. Batch galvanizing after hot stamping could provide a simple solution to this complex problem.

A commercial high strength martensitic steel containing 13 wt. \% Cr, 0.35 wt. \% Si, 0.3 wt. \% Mn and 0.15 wt. \% carbon has been galvanized with a commercial zinc alloy. Galvanizing produces a $\sim 15 \mu \mathrm{m}$ thick coating that is bright, continuous and metallurgically bonded. The intermetallic layer is made of $\varsigma$ crystals, which forms an open 3-dimensional structure. Tin, nickel and aluminium are found able to moderate the Sandelin effect. Comparison with other steels galvanized the same way indicates that chromium slows down the kinetics of the metallurgical reaction. Chromium distributes both in the $\varsigma$ and $\eta$ phases, and follows a diffusion-like profile in the coating. The nickel from the alloy concentrates in the Fe-Zn intermetallic compound. Aluminium segregates at the surface and interface. It also provides a gettering effect that fixes silicon in sub-micron particles dispersed in the $\varsigma$ and $\eta$ phases. Tensile experiments and fatigue tests demonstrate that the mechanical performances of the martensitic steel are preserved after coating. Comparison with similar experiments performed on a TRIP800 steel indicates that using galvanized martensitic steel is best worth in static applications.
\end{abstract}

Keywords: Galvanizing, martensite steel, zinc alloys, mechanical properties, corrosion. 


\section{Introduction}

Advanced High Strength Steels (AHSS) can contribute to reduce the lightweight of vehicles since thin sheets of AHSS produce the same mechanical resistance as thick parts made of common steel. The remarkable mechanical properties of these AHSS are due to optimised grades, and to microstructures resulting of sophisticated thermomechanical processes. Protection against corrosion is essential for using high strength steels in practical applications because the permanency of the mechanical resistance of thin sheets is more sensitive to corrosion. The use of AHSS cannot be seriously envisaged as far as complete solutions including anticorrosion protection are provided. Hot galvanizing is one of the most efficient and cheapest ways to protect steels against corrosion. The sacrificial zinc layer provides the cathodic protection. It is admitted that the duration of the protection is proportional to the amount of zinc in the coating [1].

Hot galvanizing refers to various practices, using specific alloys and producing different coatings [1]. Marder focussed his paper mainly on continuous galvanizing [2]. Continuous galvanizing produces a coating about $12 \mu \mathrm{m}$ thick, made of pure $(\eta)$ zinc because a thin intermetallic layer inhibits the reaction of zinc with the iron substrate [3]. Coatings made of $\mathrm{Zn}-\mathrm{Al}$ alloys are also produced by continuous galvanizing. Galvannealing consists in a fast re-melting of the coating of specifically designed galvanized steel in order to produce a fully alloyed $\delta$ layer. In continuous galvanizing, hot-dipping and annealed last for seconds. Metallurgical aspects of general batch galvanizing have been described by Makowiak and Short [4]. Batch galvanizing is used to produce thicker coatings $(45-150 \mu \mathrm{m})$ through the growth of a stratified layer made of the full range of intermetallic Fe-Zn compounds. The dipping lasts minutes, and the kinetics of growth is generally parabolic (i.e. the thickness of the layer follows a square root law versus the dipping time). Silicon killed steels and steels containing phosphorus raise a specific difficulty in galvanizing because silicon and phosphorus delay the nucleation of the $\varsigma$ phase on the steel during hot-dipping, preventing the formation of a stable and passivating layer in the bath, and disrupting the parabolic growth. When it is not mastered, this effect, known as the "Sandelin effect", produces grey and irregular coatings due to so-called "outbursts", which are patches of uncontrolled $\varsigma$ growths [5]. Steels whose compositions $(\mathrm{Si}+2.5 \mathrm{x} \mathrm{P})$ approach and exceed $0.1 \mathrm{wt} . \%$ are prone to this phenomenon, and are called "Sandelin" or "hypersandelin" steels [6]. So, galvanizing new steels raises questions, since the process can be affected by the composition of the steel. Moreover, the mechanical performances of galvanized AHSS could be modified if the microstructure of the steel in the bulk is changed during the dipping in melted zinc, or if the microstructure of the coating is prone to start fatigue cracks [7].

The present work assays if hot-dip galvanizing can produce a protective coating on high resistance high-chromium martensitic steels and preserve their mechanical performances. As a matter of fact, figure 1 presents the $\mathrm{Fe}-\mathrm{Cr}$ phase diagram. One sees that a chromium concentration between 0 and 14.3 wt. $\%$ stabilises the austenite required to produce martensite, in the $\gamma$ loop between $846^{\circ} \mathrm{C}$ and $1394{ }^{\circ} \mathrm{C}$. The $\sigma$ phase with a Fe/Cr ratio close to $50 / 50$ is stable between 440 and $830^{\circ} \mathrm{C}$. This high temperature phase appears and precipitates in a large range of composition, and an eutectoid transformation occurs at $440^{\circ} \mathrm{C}$ during cooling. The production of both the brittle $\sigma$ phase and eutectoid compound are detrimental for top ranking mechanical properties [8]. We have used commercial martensitic steel containing $13 \mathrm{wt} . \% \mathrm{Cr}$ and $0.15 \mathrm{wt} \% \mathrm{C}$. This composition enables the formation of martensite, and limits or prevent the formation of both the brittle $\sigma$ phase and the eutectoid structure. Our steel also contains $0.40 \mathrm{wt} . \% \mathrm{Mn}$ and $0.35 \mathrm{wt}$. \% $\mathrm{Si}$ in order to stabilize 
residual austenite and delay the formation of carbides. Both martensite and residual austenite contribute to form a fine composite microstructure that provides with both excellent mechanical resistance and high ductility. Our study is focussed on the reactivity of this chromium-rich steel with the galvanizing alloy, because it is expected to be an hypersandelin steel, and also because, to our knowledge, the reactivity of chromium-rich steels has not yet been documented in the literature. We also evaluate the mechanical properties of this steel after galvanizing.

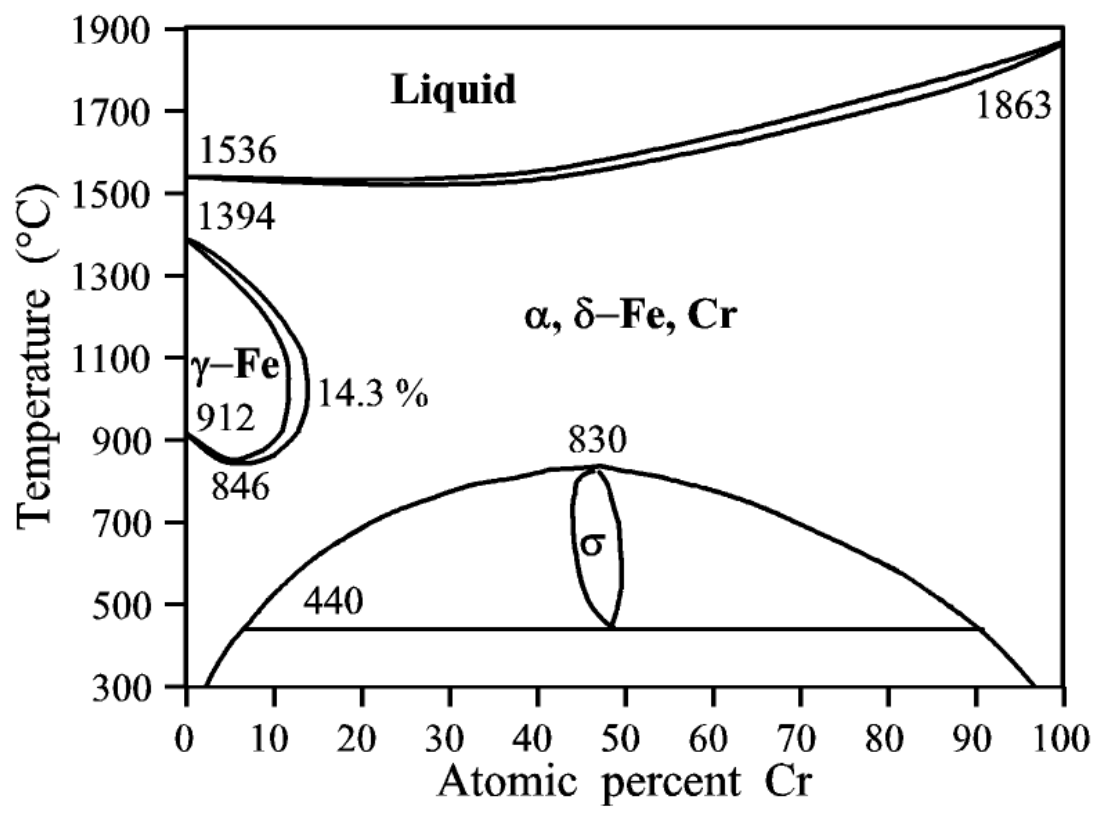

Figure 1: Fe-Cr phase diagram

The very strong martensitic steels are good candidates for making strengthening bars and structural parts of cars. The corrosion resistance of chromium-rich martensitic steels is higher than the one of standard steels. Nevertheless, it is lower than the one of other stainless steels because the chromium concentrations is lower than in other stainless steels. Moreover, there is no nickel in this steel, and the level of carbon is high. The lower corrosion resistance stands despite of their silicon and manganese contents $[9,10]$. Now, structural parts are often located at the bottom of cars where they are exposed to aggressive corrosion. Moreover, they are often made of several steel grades in order to combine rigidity, fatigue toughness and sophisticated behaviour during crash. So, localised corrosion and passivity breakdowns due to pitting could be expected on composite parts in chloride - and acidic- wet media [11]. The phenomenon is accelerated if the combination of several steels produces galvanic couples. For these reasons, composite parts at the bottom of cars should be galvanized in order to reinforce corrosion resistance and to level the electrochemical potential (cathodic protection).

Hot-dip galvanizing after fabrication is an option to be considered in these applications not only because it produces thick coatings, but also because forming pre-coated AHSS is a delicate challenge that is not solved so far. Cold forming of strong martensite requires several passes. It has not yet been possible to find a coating applied before drawing that could resist to fissuring or scaling during forming because stresses and shears reach high levels due to the high yield and work hardening of martensitic steel ( $\mathrm{Y}=990 \mathrm{MPa})$. Hot forming and formingquenching could be easier $(\mathrm{Y}=550 \mathrm{MPa})$ [12]. However, the interface between the steel and the coating must be chemically stable at high temperature when hot forming is envisaged. Moreover, the thermomechanical stress generated during austenization at $990^{\circ} \mathrm{C}$ and 
quenching must not delaminate the coating. Coating after forming could simplify the problem.

The introduction of a new steel grade in the fabrication of cars raises lots of new problems and questions. They cannot be all addressed in a single paper.

The first question presently treated is to determine if chromium-rich martensite can be properly galvanized. As a matter of fact, the high silicon concentration in this martensitic steel could modify the reactivity in the bath due to the Sandelin effect. Chromium could also form specific intermetallic compounds. To our knowledge, these effects have not yet been studied. On the other hand, the peculiar oxide scale built on the stainless steel during the thermomechanical activation treatment could interfere with the surface preparation step involved in the process. This possible interference has to be evaluated. For this reason, the chemistry of the surface after continuous annealing was left unchanged before the coupon entered the industrial process.

The second part of the present paper focuses on the effect of galvanizing on the mechanical properties of the high-chromium martensitic steel. Since galvanizing is the final step of fabrication, it should not deteriorate the mechanical performance previously optimised, for instance, by forming-quenching. Indeed, tempering, bainitic transformation, or precipitation of a brittle phase during hot dipping in the bath could modify the bulk properties of martensite. The behaviour law provided by tensile tests is sensitive to such changes. Galvanizing could also affect the fatigue toughness because fatigue cracks usually starts at the surface. Measurements of the resistance to fatigue must be linked to a precise observation of the microstructure of the coating. In a general scientific approach, the evolution of mechanical properties is presently evaluated using recognised standard test procedures on flat samples. For this reason, and also in order to get a higher sensitivity of eventual degradations, galvanized and bare samples were prepared from steel trips whose mechanical properties were initially optimised by continuous annealing.

\section{Experimental}

Our samples were machined from 2-mm thick steel sheets. The steel grade is the commercial EN 1.4006 / ASI 410 grade from Arcelor-Mittal. The composition is as follows: C : $0.15 \mathrm{wt}$. $\%$; Cr : 13 wt. \% ; Si : 0.35 wt.\% ; Mn : 0.40 wt. \%. Nickel and molybdenum concentrations are at minimum. In the annealed state commercially available, this steel usually provides with a mechanical resistance $(\mathrm{Rm})$ of $545 \mathrm{MPa}$, and total elongation (A) of $28 \%$. For the present study, in order to form martensite, keep some residual austenite, and limit the formation of the brittle eutectic structure and $\sigma$ phase, our sheets followed an optimised thermo-mechanical treatment in a continuous annealing line. The annealing was performed in a reducing atmosphere with a very low dew point $\left(-50^{\circ} \mathrm{C}\right)$. The mechanical properties obtained that way model the one of pieces produced by hot stamping.

The surface chemistry after continuous annealing was kept as such before entering the industrial coating process, which has been optimised for the automotive industry at Galva45's (France). Surface preparation includes degreasing, pickling and fluxing steps according to the present industrial state of the art [13]. Galvanizing is performed in a commercial zinc alloy (Galvacar ${ }^{\circledR}$ ) able to moderate the Sandelin effect with small amount of aluminum, bismuth, tin and nickel [14]. The samples stayed in the bath at $445^{\circ} \mathrm{C}$ during 3.0 minutes. The speed of withdrawal was $0.0085 \mathrm{~m} / \mathrm{s}$. 
A first advantage of our procedure is that the microstructure of the steel in the bulk is optimised without deformation. Then the mechanical properties of our flat samples can be analysed by standard testing. A second advantage is that the surface mechanical properties and chemistry are not affected by possible surface degradation due to scratches, defects, nonuniform stresses and strains produced during cold or hot deep drawing. Presently, the effects of galvanizing on the material properties are specifically analysed because they are observed on homogeneous surfaces without interference due to uncontrolled surface disorders.

Galvanized samples underwent classical metallographic preparation including grinding on $\mathrm{SiC}$ papers down to 4000 grains $/ \mathrm{m}^{2}$. The microstructure of the intermetallic compound into the coating naturally appears after polishing because the different electrochemical potential of zinc and of the intermetallic compound produces spontaneous and localised electrochemical erosion. The tri-dimensional microstructure of the intermetallic phase is revealed by selective etching using a solution of Nital with $5 \% \mathrm{HNO}_{3}$ in ethanol. Etching during $30 \mathrm{~s}$ at room temperature dissolves 3-5 $\mu \mathrm{m}$ of zinc.

Metallurgical microstructures were observed using a JEOL field emission scanning electron microscope (JSM 6500) equipped with a BRUKER - Quantax microanalysis system based on an energy dispersive spectroscopy facility. X-rays for EDX analyses were excited with 20 $\mathrm{keV}$ electrons. The lateral resolution of EDX analyses is $\sim 2 \mu \mathrm{m}$. It corresponds to the secondary electrons ranges of interactions and to the X-ray fluorescence range of excitation, which far exceed the size of the electron beam.

The atomic compositions were evaluated from the EDX measurements using standard ZAF corrections without specific composition standards. Predictions of the analysis routine have been checked and validated on known samples. The concentration of manganese cannot be measured precisely by EDX because Mn lines superimpose the ones of $\mathrm{Cr}$ and Fe. So, data related to manganese are not provided in the paper.

Mechanical tests were carried out, at room temperature. For both quasi-static and fatigue tests the tensile direction was perpendicular to the one of rolling. The effective length of samples used for traction and fatigue tests are respectively $30 \mathrm{~mm}$ and $18 \mathrm{~mm}$. Uniaxial quasi-static tests (strain rate of $10^{-3} \mathrm{~s}^{-1}$ ) were performed with an INSTRON electromechanical test machine with a maximal capacity of $250 \mathrm{kN}$. Concerning the hot-dip galvanized samples; it should be noted that the total thickness including the zinc coating was accounted for the applied fatigue stresses.

The fatigue tests were performed to failure with a servohydraulic SCHENK device capable of applying axial loads up to $100 \mathrm{kN}$, with a sinusoidal load wave, a frequency of $30 \mathrm{~Hz}$ and a strength ratio $\mathrm{R}=\frac{\sigma_{\min }}{\sigma_{\max }}=0.1$.

\section{Results and discussion}

\subsection{Microstructure of the coating}

\section{$\underline{\text { 3.1.1 Microscopy }}$}

Galvanizing of the chromium-rich martensitic steel produces bright and continuous coatings metallurgically bonded to the substrate. A visual observation reveals that $\eta$ spangles extend over several centimetres in length. (The $\eta$ phase is the hexagonal $\mathrm{Zn}$ ). Grains grow preferentially in the direction of solidification when samples exit the bath. Grain boundaries 
of the $\eta$ phase are closed and difficult to observe. The initial surface of the laminated steel sheets is rough. Galvanizing flattens the surface because the surface tension of liquid zinc is high. The maximum point to point roughness after coating is lower than $5 \mu \mathrm{m}$. A very small amplitude $(<1 \mu \mathrm{m})$ peculiar roughness can be observed at high magnification (figure 2$)$. This roughness is not due to lacks or pits. Point and line EDX analyses along the surface reveal that it is associated to droplets of tin and to the outcrop of grains of the underlying intermetallic compound above outbursts (figure 3 ).

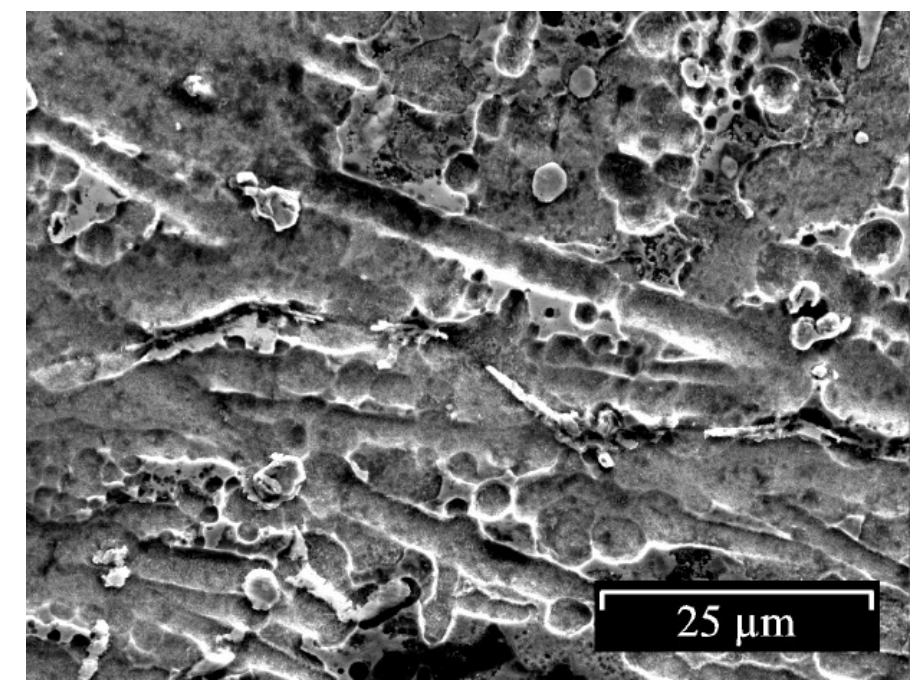

Figure 2 : SEM micrographs of $\eta$ surface grains.

Figure 3 to 5 present cuts through the coating. Figure 3 reveals that the intermetallic layer is mainly made of filaments of the $\varsigma \mathrm{Fe}-\mathrm{Zn}$ phase. $\varsigma$ filaments are usually produced with alloys containing tin [15]. Figure 3 focuses the attention on what is called an "outburst". Outbursts are localised growths of the intermetallic compound. Outbursts are usual in coatings on hypersandelin steels (silicon concentrations superior to $0.1 \mathrm{wt} \%$ ) $[2,15]$. The outburst on figure 3 is obviously the result of a reaction started after the piece was withdrawn from the bath since the growth is limited by the surface of the $\eta$ layer.

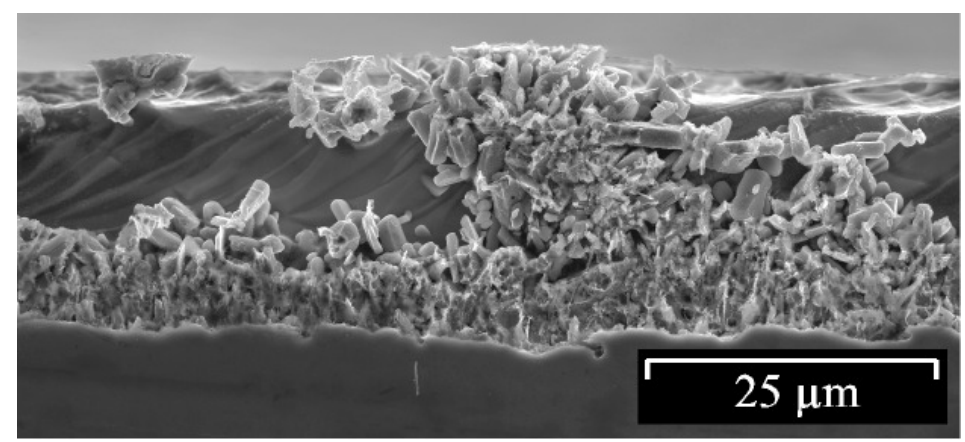

Figure 3: Tri-dimensional structure of an "outburst" viewed from the side of a cut through the coating. (Sample etched with Nital $5 \%$ during $30 \mathrm{~s}$ )

Figure 4 shows a close view of the microstructure of the intermetallic compound after that a chemical etching $30 \mathrm{~s}$ with Nital has removed the $\eta$ phase over microns. This etching reduces the apparent thickness of the coating, but reveals the tri-dimensional structure of the intermetallic compound. $\varsigma$ grains are narrow and long. Most of them are branched. They are connected together and line up to form filaments in the 45 to $100 \mu \mathrm{m}$-thick layers (not 
presented here). The $\eta$ phase (pure zinc) fills the space between the entangled $\varsigma$ filaments. This observation enables to understand that liquid zinc is captured by capilarity into the $\varsigma$ filaments when the part leaves the bath. The $\varsigma$ phase levels the surface. The delta phase $(\delta)$ layer which is usually thin on hypersandelin steels galvanized with alloys containing tin, is hardly distinguishable on our cuts, even in the 45 to $100 \mu \mathrm{m}$-thick layers (not presented here).

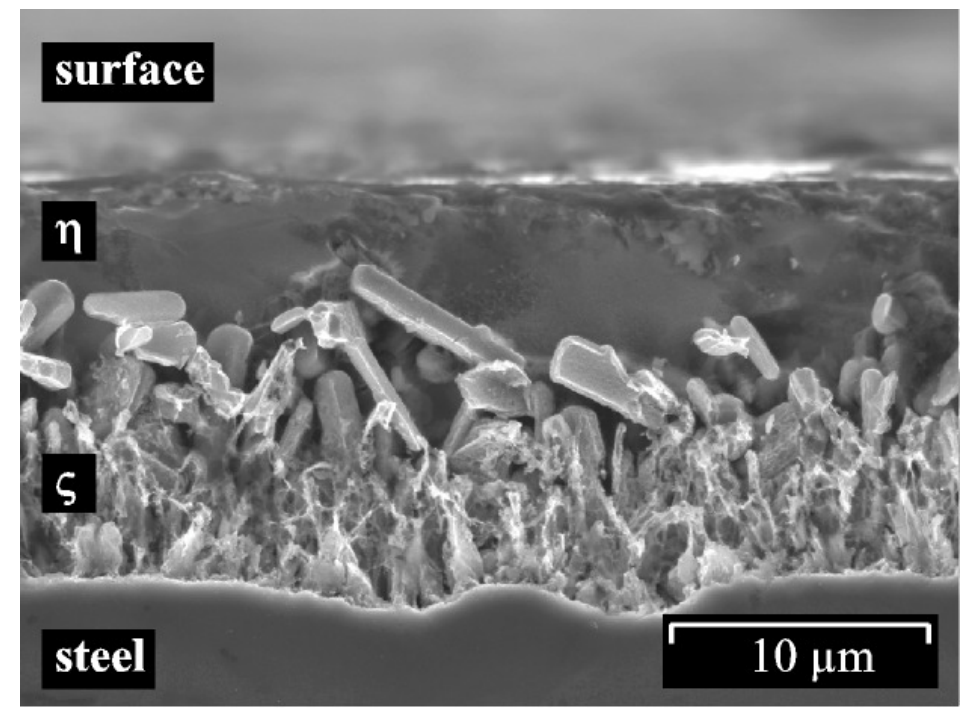

Figure 4: Side view of the coating microstructure. Deep etching reveals the tridimensional microstructure of the inter-metallic compound.

Protection against corrosion is proportional to the overall thickness of the layer. The full thickness of the coating is the sum of the length of the filaments added to the thickness of the $\eta$ layer. The surface tension and viscosity of the alloy, as well as conditions of withdrawing determine the last. Figures 3 to 5 shows that the average total thickness of the coating is presently $15.5 \pm 1 \mu \mathrm{m}$. This thickness varies locally by about $\pm 10 \%$ spot by spot on a single sample due to the initial roughness of the laminated sheet. $\varsigma$ filaments are similar in length all over the surface except at the place of outbursts. Their length increases with dipping time, and depends on the reactivity of the steel grade in the melted alloy. Microstructures and thickness are similar on both sides of the galvanized steel sheets at $\pm 5 \%$.

Figure 5 presents a side view of a cut without acid pickling. The border of the $\varsigma$ phase is revealed by a selective electrochemical etching of zinc during polishing. This etching evidences local corrosion currents in water during grinding. This galvanic coupling, which is not observed after the metallographic preparation of coatings on galvanized standard steels, indicates that the corrosion potential of the chromium-rich $\varsigma$ phase is higher than the one of the $\varsigma$ phase grown on standard steel. It can be inferred that the chromium-rich $\varsigma$ phase probably provides with a more noble corrosion behaviour than the usual $\varsigma$ phase. It is not the purpose of this paper to investigate further on this question. The arrow superimposed on figure 5 is the path of the EDX line analysis of figure 6 . 


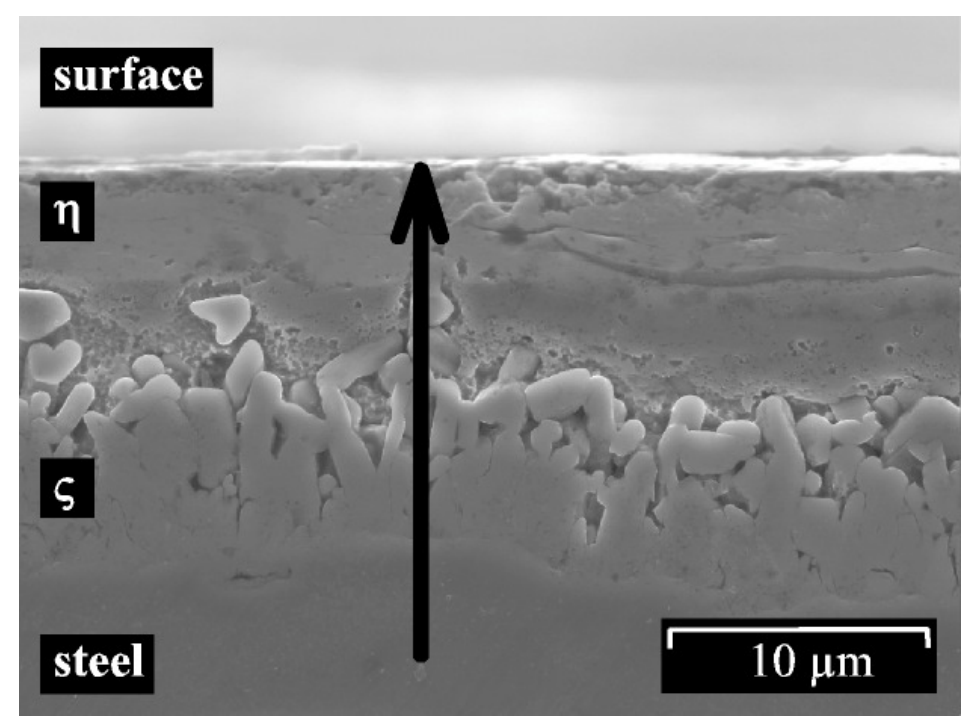

Figure 5: Side view of the coating microstructure (natural electrochemical etching during grinding). The arrow is the path of the EDX line analysis of figure 6.

\section{$\underline{3.1 .2 \text { Chemical analyses }}$}

Table 1 presents atomic compositions measured by EDX of - the steel in the bulk (from the side of a cut); - the $\eta$ phase at the surface (from the top of the layer) and in the bulk (from the side of a cut, from an area which does not include the surface); - the $\varsigma$ phase measured from the top of the sheet after selective etching of the zinc; and finally, - the whole layer from the side of a cut (average of both $\eta$ and $\varsigma$ phases). These data correspond to average composition on small areas. They are complementary to point analyses reported on figure 6 .

Table 1 : Atomic composition of steel and coating analysed by EDX.

\begin{tabular}{|l|c|c|c|c|c|c|c|}
\hline \multicolumn{1}{|c|}{ (wt. \%) } & $\mathbf{F e}$ & $\mathbf{C r}$ & $\mathbf{S n}$ & $\mathbf{N i}$ & $\mathbf{A l}$ & $\mathbf{S i}$ & $\mathbf{B i}$ \\
\hline Steel (bulk) & 87.0 & 12.6 & $\mathrm{ND}$ & $\mathrm{ND}$ & $\mathrm{ND}$ & 0.4 & $\mathrm{ND}$ \\
\hline$\eta$ (at the surface) & $\sim 0.7$ & $\sim 0.15$ & $\begin{array}{c}\text { Var : } \\
3-20 \%\end{array}$ & traces & $0.4 \pm 0.2$ & $<0.4$ & traces \\
\hline$\eta$ (bulk) & $\begin{array}{c}\text { Var : } \\
1-5 \%\end{array}$ & $\sim 0.20$ & $\sim 3.0$ & traces & $\begin{array}{c}\text { Var : } \\
0.1-0.5 \%\end{array}$ & $\begin{array}{c}\text { Var : } \\
<0.05-1.5 \%\end{array}$ & ND \\
\hline$\varsigma$ (bulk) & 7.50 & 0.50 & 0.35 & 0.45 & 0.35 & 0.15 & 0.45 \\
\hline Coating (1) & 4.4 & 0.41 & 0.85 & 0.26 & 0.11 & 0.06 & 0.50 \\
\hline $\begin{array}{l}\text { Coating (profile } \\
\text { and soft etching) }\end{array}$ & 6.0 & 0.5 & $\begin{array}{c}\text { Var : } \\
0-4 \%\end{array}$ & NA & $\begin{array}{c}\text { Var : } \\
0.2-0.6\end{array}$ & $0.2 \pm 0.2$ & NA \\
\hline Coating (2). & 12 & 1.7 & 3.0 & 0.6 & 0.3 & 0.12 & $0.85 \pm 0.5$ \\
\hline
\end{tabular}

$\mathrm{ND}=$ not detected $(<0.1 \mathrm{wt} . \%) ; \mathrm{NA}=$ not available $; \mathrm{Var}=$ changing from one point to another due to particles. (1) analysis from the side of a cut, without etching with Nital (the analysed area does not include the surface of the coating) - (2) analysis from the side of a cut, after etching with Nital $5 \%$ (30s) (hard etching). 
The EDX analysis of the steel gives a mean composition for $\mathrm{Fe}, \mathrm{Si}$ and $\mathrm{Cr}$, which are close to the one communicated by the steel maker. It is a check to verify that routine EDX analysis provides with reliable quantitative results. The $\mathrm{Fe} / \mathrm{Cr}$ ratio is between 7.0 to 8.0.

EDX analysis on bare samples was not able to detect a significant modification of the surface composition. So, hot rolling and continuous annealing in reducing atmosphere limit the segregation of silicon and chromium to the surface and their oxidation.

The analysis of the zinc $(\eta)$ layer from the surface of the coating suggests an iron concentration exceeding the limit of solubility at $450^{\circ} \mathrm{C}(\sim 0.01 \mathrm{wt} . \% \mathrm{Fe})$, and large variations from place to place. Variations are related to $\varsigma$ particles dispersed in the layer (cf. figure 3 and 4). The apparent excessive iron concentration measured by point EDX analyses between $\varsigma$ grains is an artefact due to fluorescence of the iron atoms excited by the bremsstrahlung and $\mathrm{Zn}$ X-ray lines. The comparison of the aluminium concentrations on the surface of the $\eta$ phase and in the bulk of the $\eta$ phase confirms the expected segregation of aluminium towards the surface.

The intermetallic $\varsigma$ compound has been analysed from the top after the $\eta$ zinc has been selectively dissolved. This bulk analysis of the $\varsigma$ compound indicates an iron concentration ( 7.5 wt. $\% \mathrm{Fe}$ ) closer to the one of the pure $\mathrm{Fe}-\mathrm{Zn} \delta$ phase $(11.8-6.9 \mathrm{wt}$. \% Fe) than the one of the pure $\varsigma$ phase (6.2-5.2 wt. \% Fe). However, the morphology of the Fe- $\mathrm{Zn}$ phase in the present sample is closer to the one of the usual $\varsigma$ phase than to the one observed on $\delta_{\text {compact }}$ (compact layer) or $\delta_{\text {palissade }}$ (fine platelets) phases [15]. EDX maps (not presented here) indicate that the elements analysed in $\varsigma$ grains are evenly distributed; except tin and bismuth, which are correlated and preferentially located at grain boundaries. The $\mathrm{Fe} / \mathrm{Cr}$ intensity ratio is about 15.0. The chromium concentration is then much lower than the one in the bulk of steel. Nickel, aluminium and silicon are unambiguously detected. The alloy provides with nickel and aluminium; silicon comes from the steel. Silicon which has a low solubility in the $\eta$ phase precipitates in the same volume than the $\varsigma$ phase. However, the analysis of the bulk $\varsigma$ phase does not help to decide if aluminium and silicon are incorporated into the structure of the $\varsigma$ phase, or if they accumulate at the surface of $\varsigma$ grains.

The average compositions of the coating have been measured on three samples without and after progressive selective etching by Nital. Since the Nital preferentially removes the $\eta$ phase, a decrease of the average concentration of an element is correlated to a higher concentration in the $\eta$ phase. The Fe / Cr ratio changes from 7 to 10 according to the etching depth. This is coherent with the analysis of the bulk $\varsigma$ phase. This confirms that the concentration of chromium is higher in the $\eta$ phase than in the $\varsigma$ phase. Selective etching with Nital promotes the sensitivity to tin, and enables to detect bismuth. Nickel and aluminium signals seem to be higher in the $\varsigma$ phase, but their variations are not sufficient to be completely conclusive. The evolution of the Si EDX signal versus nital etching suggests that silicon could be preferentially located in the $\varsigma$ phase.

A better knowledge of the location and spatial distribution of chromium, nickel, tin, aluminium and silicon into the layer is of particular interest in order to identify the phenomena controlling the growth. The anisotropy in the coating explains that some average analyses in table 1 are difficult to interpret. Line EDX analyses and 2-D EDX mapping have been acquired in order to observe the distribution of concentrations and correlations between elements in the coating. EDX maps are not presently shown and described in detail because main conclusions are found in line analyses. Moreover, line analyses provide a better ground to discuss quantitative information. 
Figure 6 shows the results of an EDX line analysis performed on a cut, across the coating, from the substrate to the surface (see fig. 5). The interface between the substrate and the coating is located at 2.5-3.0 $\mu \mathrm{m}$ from the origin of the scale. Figure 5 shows that the line crosses $\varsigma$ grains when co-ordinates on the scale are between 3 and $14 \mu \mathrm{m}$, and go along a grain boundary between 7 and $9 \mu \mathrm{m}$.
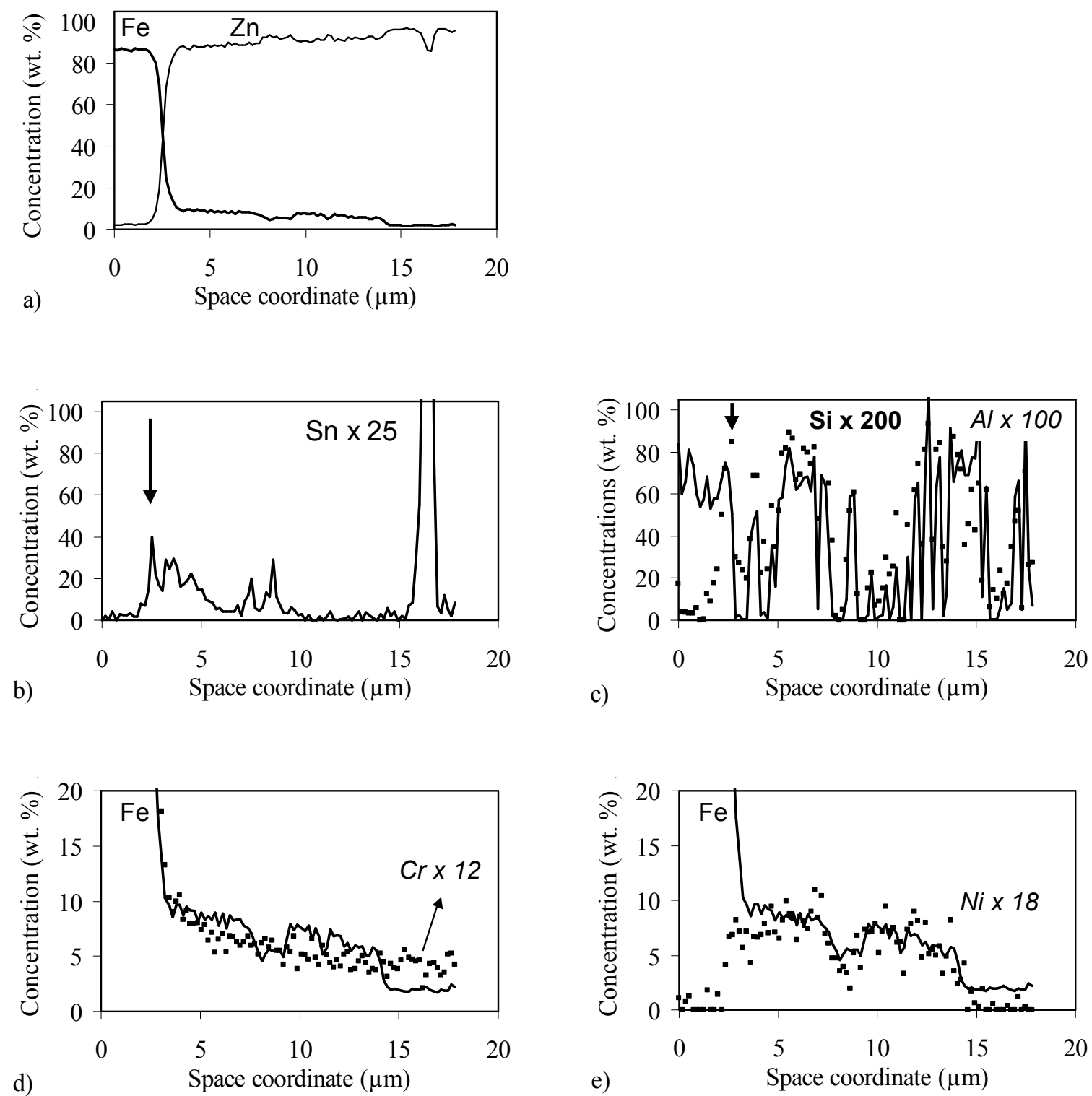

Figure 6: EDX line analyses across the coating (the line follows the path visible on figure $5)$.

The signals of iron and zinc let see a sharp interface between the coating and the substrate (fig. 6a). The iron concentration progressively diminishes across the layer of the intermetallic compound, indicating that the $\eta$ zinc fills the space between $\varsigma$ grains and that the 3-D structure of the $\varsigma$ phase opens at the top. The intensity of the X-rays from tin indicates accumulation in the intermetallic layer close to the interface with steel (fig. 6b). The large and fast variations of the spatial distribution of intensity suggest that tin is finely dispersed and randomly distributed at boundaries. A droplet of tin is visible at $16 \mu \mathrm{m}$ on the scale. Tin segregates from the $\eta$ zinc matrix since the $\mathrm{Zn}$ signal is reduced at this place. 
The average silicon concentration in steel is about $0.35 \pm 0.05 \mathrm{wt} . \%$ (fig. $6 \mathrm{c}$ ). The variance is due to the poor signal/noise ratio and to the artefact caused by the fluorescence of Si into the detector. The silicon and aluminium concentrations in the $\varsigma$ and $\eta$ phases varies suddenly from place to place $(0.2 \pm 0.2 \mathrm{wt} . \% \mathrm{Si})$. The aluminium and silicon concentrations are correlated, and the $\mathrm{Si} / \mathrm{Al}$ ratio of concentrations is $\sim 1 / 2$. Their rapid variations are not only due to signal statistics. Silicon and aluminium is probably concentrated in micron-size or submicronic grains $(<0.3 \mu \mathrm{m}$ in diameter). These particles produce no contrast on SEM images and are not visible on pictures. They probably accumulate at $\varsigma$ grain boundaries with the excess of zinc and/or tin because variations are visible both in the $\varsigma$ and $\eta$ phases. For this reason, these grains have been removed with the zinc initially at this place by the corrosioninduced selective electrochemical etching during grinding. Repeated experiments and mappings have shown that aluminium also concentrates at the interface with steel, and at the surface of the $\eta$ layer. This observation is not surprising since aluminium is added in the alloy in order to moderate the Sandelin effect, and to slow down the oxidation of the zinc bath (surface segregation of aluminium enhances the shiny aspect of the coating).

The chromium concentration decreases progressively into the coating following a diffusionlike profile starting from the interface with steel (fig. 6d). The poor correlation of $\mathrm{Cr}$ and $\mathrm{Fe}$ signals suggests that $\mathrm{Cr}$ is not strongly partitioned between the $\eta$ and $\varsigma$ phases. The $\mathrm{Fe} / \mathrm{Cr}$ ratio is higher $(\sim 12)$ than in the substrate $(\sim 8)$. So, the chromium atoms are not fully integrated into the $\varsigma$ phase: chromium probably also dissolves into the bath. This observation enables to understand the apparent discrepancies about chromium concentrations in table 1 . Nickel atoms, initially in the alloy, proceed in the opposite direction and strongly concentrate in the $\varsigma$ phase (fig. 6e). A strong affinity of nickel with iron is probably the cause of this phenomenon.

\section{$\underline{3.1 .3 \text { Mechanisms of reactivity }}$}

The thermodynamics of $\mathrm{Fe}-\mathrm{Zn}-\mathrm{Cr}$ and $\mathrm{Fe}-\mathrm{Zn}-\mathrm{Cr}-\mathrm{Al}$ systems have been scarcely studied [16, 17]. Formations of binary (Fe-Si, Fe-Cr) and ternary (Fe-Si-Cr, Fe-Zn-X : X = Mn, Cr, Si) compounds are expected [16-21]. It could be inferred from these phase diagrams that tin and nickel could fix the silicon from the steel in the intermetallic compound [18-20]. Our results show that aluminium and nickel effectively contribute to master the Sandelin effect on silicon- and chromium-rich martensitic steel since the metallurgical reaction produces a $\varsigma$-like intermetallic compound containing nickel and chrome. The gettering effect of aluminium is highlighted by the fact that silicon gathers with aluminium in particles finely dispersed in the $\eta$ and $\varsigma$ phases across the coating. Aluminium also segregates at the surface and at the interface with steel.

Chromium interferes in galvanizing since the metallurgical reaction on the chromium-rich steel produces a coating thinner than on other silicon-rich steels galvanized in similar conditions. Chromium sharing between the $\varsigma$ and $\eta$ phases is understood because the limit of solubility of chromium in zinc at $450^{\circ} \mathrm{C}$ is relatively high $(0.75 \mathrm{wt} . \% \mathrm{Cr})$ [22]. The relatively high solubility of chromium in zinc explains that the $\mathrm{Zn}_{17} \mathrm{Cr}$ compound does not nucleate, and suggests that chromium from the steel partially dissolves into the bath. The situation for manganese is probably similar to the one of chromium, since the limit of solubility of manganese in zinc at $450^{\circ} \mathrm{C} \sim 1.8 \mathrm{wt} . \% \mathrm{Mn}$. Manganese could also bind to tin and silicon [2324]. However, EDX analyses cannot settle this point.

The segregation of tin at grain boundaries in the $\varsigma$ layer probably results from a chemical affinity of tin towards iron and silicon lower than zinc, aluminium and nickel. Tin can also fills shrinkhole and cracks produced into the compact layer upon contraction, during cooling. 
As a matter of fact, liquid tin is the last phase to solidify [20]. The correlation of Bi and $\mathrm{Sn}$ EDX signals suggests that bismuth is mainly dissolved in tin. The formation of tin droplets in the $\eta$ layer is attributed to the gap of miscibility in liquid zinc at $450^{\circ} \mathrm{C}$.

\subsection{Mechanical properties}

\subsubsection{Tensile and fatigue tests}

In order to be more sensitive to possible degradation of the mechanical performance after galvanizing (due to precipitation of carbides or tempering), the martensitic steel was conditioned through an optimal thermo-mechanical route. The stress-strain curves of the martensitic steel before and after galvanizing are displayed on figure 7. It is concluded that the bulk mechanical constitutive law of the chromium-rich martensite is not changed after galvanizing.

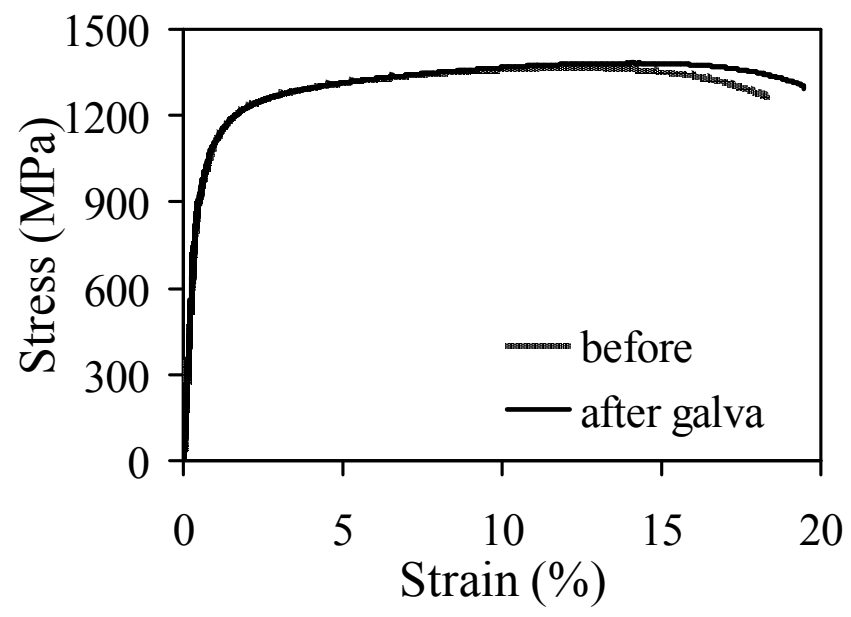

Figure 7: Conventional representations of the constitutive law of the martensitic steel before and after galvanizing.

The Young modulus is between 210 and $220 \mathrm{GPa}$. The conventional $\mathrm{Rp}_{0.2}$ yield strength is reached at $990 \mathrm{MPa}(\mathrm{Y}=990 \mathrm{MPa})$. The ultimate strength $(\mathrm{Rm})$ is observed at $1480 \mathrm{MPa}$, and the rupture occurs after an elongation $\left(\mathrm{A}_{\max }\right)$ between 17.7 and $18.7 \%$ taking into account the springback $\left(\varepsilon_{1 \mathrm{p}}\right)$.

The true mechanical constitutive law has been calculated using the following relationships:

$$
\begin{aligned}
& \varepsilon_{1}=\int_{L_{0}}^{L_{1}} \frac{d l}{l}=\ln \frac{L_{1}}{L_{0}}=\ln \left(1+\frac{A}{100}\right)=\varepsilon_{1 e}+\varepsilon_{1 p}=\frac{\sigma}{E}+\varepsilon_{1 p} \\
& \sigma=\frac{F}{S}=\frac{F}{S o} \cdot \frac{1}{\left(1-2 \cdot v \cdot \varepsilon_{1 e}-\varepsilon_{1 p}\right)}, \text { assuming }: \mathrm{v}=0.28 .
\end{aligned}
$$

The Ludwik law : $\sigma=\sigma_{0}+\mathrm{k} \cdot \varepsilon^{\mathrm{n}}$ fitted on the true stress-strain curve shows a work hardening coefficient (n) equal to 0.124 . On the rational curve, necking starts at $14.5 \%$ of deformation when rupture occurs at $16 \%$ of deformation. Martensite provides mechanical strength. Austenite is stabilised by silicon and manganese. The martensitic transformation upon deformation provides with continuous work hardening and delays necking.Since fatigue 
resistance can be affected by surface modifications, the endurance of the martensitic steel has been compared before and after galvanizing. Figure 8 shows the Wöhler curves measured with a stress ratio $R=\frac{\sigma_{\min }}{\sigma_{\max }}=0.1$. Lifetimes are presented versus the variation of stress : $\Delta \sigma=\sigma_{\max }-\sigma_{\min }$. Arrows designate the run-out specimens whose fatigue tests were stopped for a number of cycles superior to $5 \times 10^{6}$.

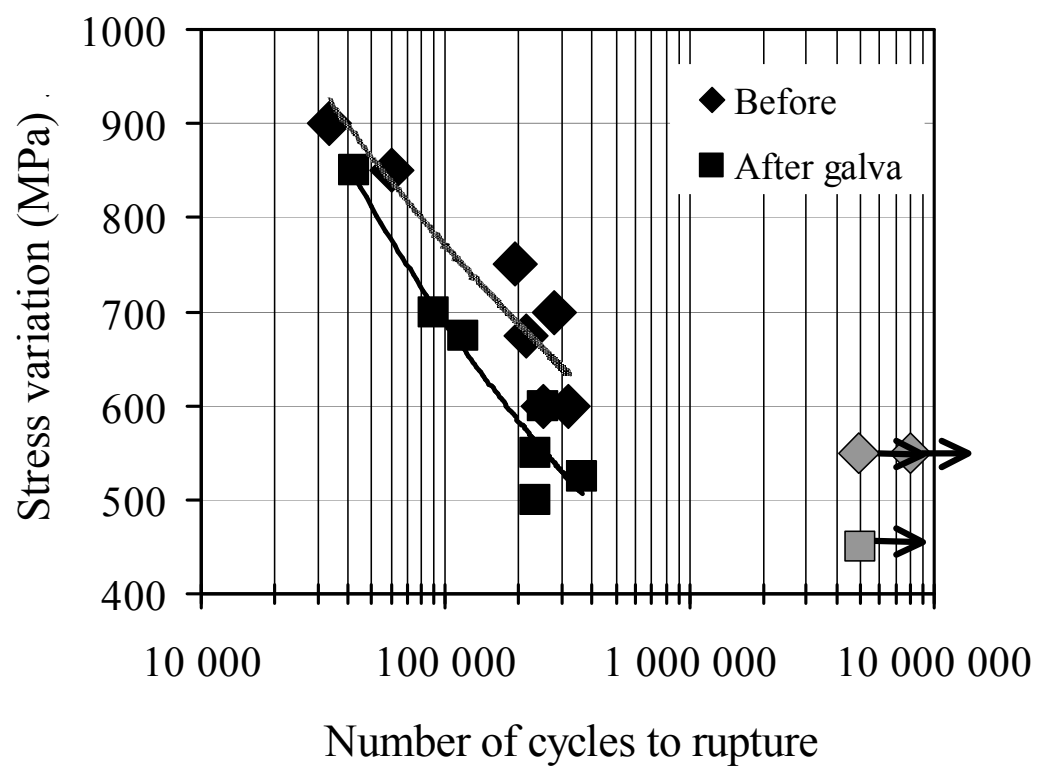

Figure 8: Wöhler curves of the martensitic steel before and after galvanizing $(R=0.1)$.

The fatigue limit is the effective resistance to be used when dimensioning structures devoted to cyclic loading. The fatigue limit of the chromium-rich martensitic steel is between 550 and $600 \mathrm{MPa}$. This value is not far from the usual $2 / 3$ factor from the yield.

Galvanizing decreases endurance by a factor 2 at $\Delta \sigma=600 \mathrm{MPa}$. The fatigue limit is lowered by $\sim 17 \%$ (to a range between 450 and $500 \mathrm{MPa}$ ). A reduction of the mechanical performances of steel is often observed after galvanizing [7]. The present deterioration is moderate and acceptable. The present results demonstrate that batch galvanizing does not degrade significantly the surface of the martensitic steel. So this steel can be used for structural applications and for the fabrication of the security reinforcement bars in the automotive industry.

\subsubsection{Interpretation and consequences for applications}

The preservation of the bulk mechanical properties after galvanizing was expected from the technical sheets (figure 9) because the mechanical properties of martensite are not significantly affected after one hour at $450^{\circ} \mathrm{C}$, because tempering of martensite proceeds very slowly at this temperature. However, this had to be checked. Since the work hardening coefficient remains constant, these tests also demonstrate that the precipitation of iron and chromium carbides at grain boundaries, as well as the continuation of the bainitic transformation of remaining austenite, are both moderate. On the other hand, the fatigue toughness of the galvanized steel, which is considered as a surface property, is not significantly degraded. This could be due to the low thickness of the coating, to the 
preferential growth of the $\varsigma$ compound and to the lack of thermally generated cracks in the coating [7, 25-27].

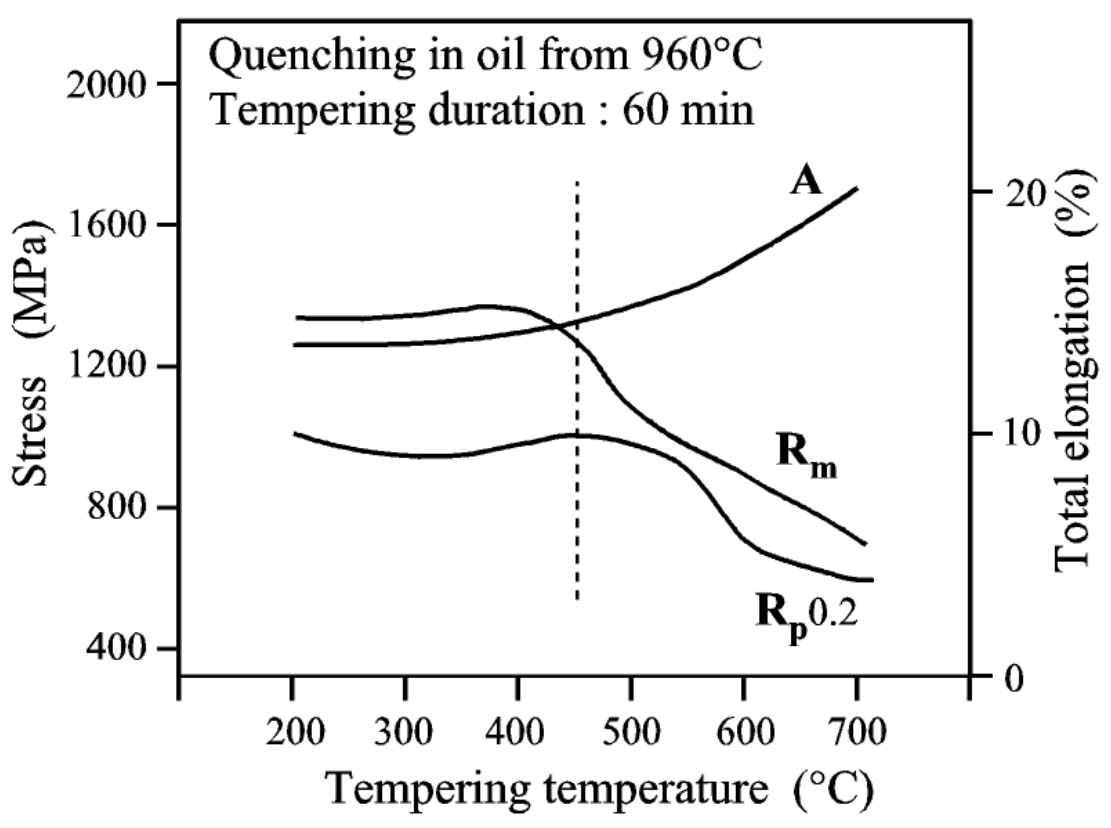

Figure 9: Yield strength, ultimate tensile strength, and maximum elongation of the chromium-rich martensitic steel after one hour tempering.

Since galvanizing preserves the mechanical performances, then, batch galvanizing after forming offers a solution against corrosion simpler than pre-coating. As a matter of fact, the coating does not need to withstand the tribological effort produced during stamping or rolling, nor thermomechanical stresses caused by the austenization and quenching.

The galvanized chromium-rich martensitic steels seem suitable for structural applications in the automotive industry. However, spot welding of martensitic steel could produce extreme hardness and fatal concentration of stresses in the field. Galvanizing contributes to circumvent this disadvantage since the production of $\mathrm{Fe}-\mathrm{Zn}$ compounds between point welded sheets contributes to improve the rigidity of welded parts thanks to brazing by zinc. Moreover, the thermal treatment association to the short stay in the bath could contribute to relieve the local residual stresses. For this purpose, thicker layer must be produced. This question is under investigation.

In a previous paper, we have reported about the evolution of the mechanical properties of a TRIP800 steel after galvanizing [7]. TRIP800 is another AHSS. The yield strength of the TRIP800 is at $\sim 650 \mathrm{MPa}$, and the one of martensite is at $990 \mathrm{MPa}$. These numbers are to be compared with a yield of 250-350 MPa for a standard steel. Both, TRIP800 and chromiumrich martensite provide with similar high level of integrated deformation energy to rupture. As a matter of fact, the stress plateau of TRIP800 upon extensive deformation is at about 800$850 \mathrm{MPa}$ and total elongation at rupture is about 23-25\%. Deformation of the chromium-rich martensite occurs in a range between 1300 and $1400 \mathrm{MPa}$, and martensite breaks at a maximum deformation close to $15 \%$. The fatigue toughness of the galvanized chromium-rich martensitic steel also compares advantageously with the one of the galvanized TRIP800, since bare TRIP800 provides a fatigue limit at $525 \mathrm{MPa}$; and galvanized TRIP800, a fatigue limit at $475 \mathrm{MPa}$ [7]. The present results show that the fatigue limit of the galvanized martensite steel is between 450-500 MPa. 
This comparison can be continued in the view of applications. The yield has to be considered as a criterion of mechanical resistance for static applications. So, the use of martensite instead of TRIP 800 can save about $30 \%$ of the weight of a part when the structural piece is for an application involving static loading. For security purpose, both steels are equal since their crashworthiness seems comparable. When dynamic loading is expected, the fatigue limit must be considered for gauging. In that case, the performances of galvanized TRIP800 seem more advantageous. The use of martensite steel is competitive for car making, because the price of steel does not contribute very significantly to the final cost of the car, and because the price increase can be paid back from the lower fuel consumption.

\section{Conclusion}

Surface processing can affect the mechanical behaviour of coated materials and structures. The reduction of steel gauge in order to save weight in vehicles makes this topic more sensitive. In this context, we have studied the galvanizability of a high-strength chromiumrich martensitic steel. We have analysed the microstructure of the coating and the evolution of the mechanical properties of the steel after galvanizing. The following summarizes the results :

- The coating is bright, continuous, and metallurgically bonded. The thickness of the coating reaches $15 \pm 1 \mu \mathrm{m}$ after 3 minutes at $450^{\circ} \mathrm{C}$. The intermetallic layer is mainly made of $\varsigma$ grains which connect together and arrange in filaments, which form an open 3dimensional structure. The $\delta$ compound cannot be detected at the interface. This microstructure is peculiar.

- This coating is suitable to level the corrosion potential of the martensitic steel on multigrade parts.

- We observe that the commercial alloy used for the automotive industry is able to moderate the Sandelin effect. Chromium interferes with galvanizing since it slows down the growth of the intermetallic compound. Chromium also dissolves into the bath. Nickel from the alloy concentrates into the $\varsigma$ phase. Aluminium segregates at the interface and at the surface. Aluminium also provides a gettering effect able to capture silicon since aluminium and silicon jointly concentrate in tiny particles dispersed both into the $\eta$ and $\varsigma$ phases. Tin segregates at grain boundaries between $\varsigma$ grains. Tin droplets separate from the zinc matrix into the $\eta$ layer and at the surface.

- Mechanical tests demonstrate remarkable high yield strength, strength resistance and total elongation before and after coating. Since, the coefficient of work hardening was neither affected by galvanizing, it is expected that martensite tempering, austenite transformation to bainite, and carbide precipiation at grain boundaries, are not significant. Moderate reduction of fatigue toughness suggests that the integrity of surfaces and grain boundaries is preserved.

- Interesting applications in the automotive industry are conceivable in order to reduce significantly the weight of vehicles. The performances of the galvanized chromium-rich martensite would worth best in structural applications involving static loading and security purpose.

The electrochemical properties of the chromium-rich intermetallic compound, surface passivation, electromigration and self-healing of scratches are important questions that must be explored in the future. 


\section{Acknowledgements}

The French ANR (Agence Nationale de la Recherche) is acknowledged for funding this research through convention ANR-06-PDIT-003-02 (research program : "GALVAsTRIP"). We are also grateful to Laurent Schmitt from Galva45 for galvanizing the samples.

\section{References}

[1] Zinc Handbook. F.C. Porter (Marcel Dekker, Southampton, UK - 1991).

[2] A.R. Marder Prog. Mater. Sci. 45 (2000) 191.

[3] E.J. Petit, J. Elia, J.S. Lecomte, V. Pitchon, B. Gay. Netsu Shori 49 (2009) 233.

[4] J. Mackowiak, N.R. Short, Int. Metals Reviews 1 (1979) 1.

[5] R. Sandelin Wire and Wire product 15 (1940) 655.

[6] B. Fenaille, M. Gilles. A new scope on the effect of silicon-phosphorus interactions on the galvanizability of steels. Proceed. $18^{\text {th }}$. Int. Galvanizing Conference (Intergalva 97) Birmingham pp.1-8.

[7] S. Aden-Ali, A. Chamat, J. Gilgert, E.J. Petit, S. Dominiak, L. Schmitt, M. Gilles, Z. Azari, Engineering Failure Analysis 16 (2009) 2009.

[8] N. Lopez, M. Cid, M. Puiggali, Corrosion Science 41 (1999) 1615.

[9] T. Ishitsuka, Y. Inoue, H. Ogawa, Oxidation of metals 61 (2004) 125.

[10] R. Peraldi, B.A. Pint, Oxidation of metals 61 (2004) 463.

[11] B.E. Wilde, E. Williams, Electrochimica acta 16 (1971) 1971.

[12] H. Takechi, J. of Metals 60 (2008) 22.

[13] D. Balloy, J.Y. Dauphin, J.C. Tissier, Surf. Coat. Technol. 202 (2007) 479.

[14] Alloy and process for galvanizing steel. International application WO98/53109, 26 nov. 1998. GILLES Mickael inventor

[15] E.J. Petit, L. Lamm, M. Gilles, J. Phys. IV 122 (2004) 69.

[16] G. Reumont, S. Maniez, B. Gay, P. Perrot, J. Mater. Sci. Lett. 19 (2000) 2081.

[17] N.Y. tang, X.B. Yu, J. Phase Equilibria and Diffusion 26 (2005) 50.

[18] N-Y. Tang, J. Phase equilibria 29 (2008) 337.

[19] V. Raghavan, J. Phase Equilibria 24 (2003) 569.

[20] M-N. Avettand-Fènoël, N. David, G. Reumont, J.-M. Fiorani, M. Vilasi, P. Perrot, J. Thermal analysis and calorimetry 90 (2007) 329.

[21] G. Reumont, P. Perrot, J. Phase Equilibria 24 (2003) 50.

[22] The solubility of metals in liquid zinc. I. Johnson and I.G. Dillon Report : ANL-7083 Argonne National Laboratory, Illinois, 1965.

[23] J.L. Liang, Y. Du, Q.Z. Zhao, C.Z. Liao, Y.Y. Tang, L.M. Zeng, W.W. Zhang, H.H. $\mathrm{Xu}$, Metall. Mater. Trans. 40A (2009) 2909.

[24] H. Xu, X. Xiong, L. Zhang, Y. Du, P. Wang, Metall. Mater. Trans. 40A (2009) 2042.

[25] T. Nilsson, G. Engberg, H. Trogen Scand. J. Metallurgy 18 (1989) 166.

[26] De la Cruz, T. Ericsson Scand. J. of Metallurgy 26 (1997) 145.

[27] J.-B. Vogt, O. Boussac, J. Foct Fatigue Fract. Engineering Mater. Struct. 23 (2001) 33. 